\title{
HUBUNGAN ANTARA SKOR IPSS DENGAN QUALITY OF LIFE PADA PASIEN BPH DENGAN LUTS YANG BEROBAT DI POLI BEDAH RSUP PROF. DR. R. D. KANDOU MANADO
}

\author{
${ }^{1}$ Cristie S. Mandang \\ ${ }^{2}$ Richard A. Monoarfa \\ ${ }^{2}$ Billy Salem
}

\author{
${ }^{1}$ Kandidat Skripsi Fakultas Kedokteran Universitas Sam Ratulangi Manado \\ ${ }^{2}$ Bagian Bedah Fakultas Kedokteran Universitas Sam Ratulangi Manado \\ Email:cmandang11_097@yahoo.com
}

\begin{abstract}
Benign prostatic hyperplasia (BPH) is a disease that is rarely life-threatening, but resulting in annoying complaints and decreasing the quality of life of the patients. BPH is found in older men. BPH patients who come for treatment are usually accompanied with lower urinary tract symptoms (LUTS). BPH patients with LUTS symptoms usually come to the clinic when they feel that the symptoms are bothering their daily-lives, therefore, decreasing the quality of life (QoL). BPH is caused by many factors, as follows: knowledge, economic, social, or cultural factors. To determine the severity of BPH with LUTS, we used the International Prostate Symptom Scoring Score (IPSS) and 1 question about the quality of life. Based on the results of cross-sectional study in December 2014 we obtained 37 patients as samples. Most patients belonged to the age group of 70-79 years (62.2\%). The majority of respondents had severe degree of IPSS score (20 patients, 54.1\%). The value of QoL scores showed that 10 patients (27\%) were not happy with their quality of life. The Spearman correlation test was used to find whether there was a correlation between the IPSS score and Quality of Life (QoL) of BPH patients with LUTS symptoms. There was a significant correlation $(\mathrm{p}<0.005)$ between IPSS-QoL $(\mathrm{r}=0.481)$. The reason that patients with symptoms of BPH LUTS came the surgical clinic of Prof. Dr R. D. Kandou Hospital Manado with severe symptoms and decreases QoL was their lack of knowledge about BPH.
\end{abstract}

Keywords: BPH, LUTS, IPSS, QoL, Manado

\begin{abstract}
Abstrak: Hiperplasia prostat jinak atau Benign Prostatic Hyperplasia (BPH) merupakan penyakit yangjarang mengancamjiwa tetapi cukup memberikan keluhan yang menjengkelkan dan menurunkan kualitas hidup penderitanya dan sering ditemukan pada pria usia lanjut. Pasien BPH yang datang berobat biasanya disertai dengan LUTS (lower urinary tract symptoms). Pasien BPH dengan gejala LUTS yang mencari pengobatan medis biasanya datang pada saat dirinya merasa bahwa gejala yang dirasakan sudah cukup menggangu aktivitas sehari-hari atau dengan kata lain, mengganggu kualitas hidupnya. Keadaan seperti ini disebabkan oleh banyak faktor, antara lain faktor pengetahuan, ekonomi, atau sosial budaya. Untuk menentukan derajat berat ringannya BPH yang disertai dengan gejala LUTS, digunakan skoring International Prostate Symptom Score (IPSS) dan 1 pertanyaan mengenai kualitas hidup. Berdasarkan hasil penelitian potong lintang yang dilakukan selama bulan Desember 2014 didapatkan 37 sampel. Insiden BPH terbanyak berada pada kisaran umur 70-79 tahun sebanyak 23 pasien $(62,2 \%)$. Derajat BPH yang paling sering ialah derajat berat sebanyak 20 pasien (54,1\%). Nilai skor kualitas hidup yang sering dirasakan pasien menunjukkan bahwa 10 pasien (27\%) merasa tidak senang dengan kualitas hidupnya. Hasil uji korelasi antara IPSSQOL didapatkan bermakna $(\mathrm{p}<0,005)$, dengan nilai $\mathrm{r}=0,481$. Faktor yang menjadi alasan mengapa pasien-pasien BPH dengan gejala LUTS yang berobat di Poli Bedah RSUP Prof. Dr.
\end{abstract}


R. D. Kandou Manado datang dengan gejala yang berat dan kualitas hidup tidak senang ialah kurangnya pengetahuan mengenai BPH itu sendiri.

Kata kunci: BPH, LUTS, IPSS, QOL, Manado

Hiperplasia prostat jinak atau Benign Prostatic Hyperplasia (BPH) merupakan penyakit yang jarang mengancam jiwa tetapi cukup memberikan keluhan yang menjengkelkan dan menurunkan kualitas hidup penderitanya dan sering ditemukan pada pria usia lanjut. ${ }^{1}$

Studi yang dilakukan di Amerika Serikat oleh Olmsted Country didapatkan prevalensi BPH mencapai hingga 13\% pada usia diatas 40 tahun dan meningkat seiring dengan bertambahnya usia. $^{2}$ Prevalensi $\mathrm{BPH}$ yang didapat dari studi multisenter yakni, di Asia lebih tinggi dibandingkan di Amerika Serikat yaitu sekitar 18\% pada usia diatas 40 tahun. ${ }^{2}$ Prevalensi $\mathrm{BPH}$ di Indonesia sendiri, belum diketahui secara pasti.

Pasien BPH yang datang berobat biasanya disertai dengan LUTS (lower urinary tract symptoms). ${ }^{3}$ Prevalensi LUTS sangat bervariasi di beberapa negara didunia, dan begitu juga di Asia. Di Singapura berkisar antara 14\%, dan di Filipina berkisar $59 \%{ }^{4}$

Untuk menentukan derajat berat ringannya $\mathrm{BPH}$, maka dibuatlah suatu skoring, salah satunya skoring International Prostate Symptom Score (IPSS) yang diambil dari American Urological Association (AUA). ${ }^{5}$ IPSS terdiri atas tujuh pertanyaan yang berhubungan dengan keluhan LUTS yang masing-masing memiliki nilai 0 hingga 5 dengan total maksimum 35 dan satu pertanyaan mengenai kualitas hidup (Quality of Life atau QoL) yang terdiri atas tujuh kemungkinan jawaban. LUTS dibagi atas ringan (IPSS 0-7), sedang (IPSS 8-19) atau berat (IPSS 20-35) tergantung pada banyaknya gejala. ${ }^{3,6}$

Tidak semua pria merasa terganggu dengan gejala LUTS, dan akhirnya mereka tidak mencari pengobatan medis. Dalam beberapa kasus, gejala ini dapat diterima sebagai hal yang wajar terjadi seiring penuaan dan belajar untuk hidup dalam kondisi itu. ${ }^{7}$ Menurut Nugroho (2002), keterlambatan deteksi dini dipengaruhi oleh persepsi penderita terhadap keluhan yang dirasakan. Gejala yang timbul terusmenerus dan dirasakan semakin mengganggu akan memotivasi penderita untuk pergi berkonsultasi pada tenaga medis dengan harapan gejala itu dapat teratasi. Dengan kata lain, skor IPSS dan QoL berperan dalam penilaian dan rencana terapi BPH. Maka dilakukan penelitian dengan metode cross-sectional untuk mengetahui hubungan antara skor IPSS dengan QoL pasien BPH dengan gejala LUTS yang berobat di poli bedah RSUP Prof. Dr. R. D. Kandou Manado.

\section{METODE PENELITIAN}

Penelitian ini merupakan penelitian bersifat analitik dengan menggunakan metode cross-sectional untuk mengetahui hubungan antara skor IPSS dengan Quality of Life. Penelitian ini dilakukan selama bulan Desember 2014, dan didapatkan 37 pasien $\mathrm{BPH}$ yang berobat dengan gejala LUTS dan masuk dalam kriteria inklusi. Penelitian dilakukan di poli Bedah RSUP Prof. Dr. R. D. Kandou Manado. Metode pengumpulan yang digunakan adalah non probability sampling yaitu dengan mengumpulkan pasien selama batas waktu yang di targetkan dalam penelitian ini yakni 1 bulan (selama bulan Desember 2014). Kriteria Inklusi dari penelitian ini adalah pasien pria yang berobat di poliklinik Bedah RSUP Prof. Dr. R. D. Kandou, yang didiagnosis dokter sebagai penderita BPH dengan gejala LUTS, pasien bersedia menjadi responden dalam penelitian ini dan pria berusia diatas 40 tahun. Dalam penelitian ini instrumen yang digunakan adalah lembar pertanyaan atau kuesioner International Prostate Symptom Score (IPSS) dan indeks QoL. 
IPSS terdiri atas tujuh pertanyaan yang berhubungan dengan keluhan LUTS yang masing-masing memiliki nilai 0 hingga 5 dengan total maksimum 35 dan satu pertanyaan mengenai kualitas hidup (Quality of Life atau QoL) yang terdiri atas tujuh kemungkinan jawaban. LUTS dibagi atas ringan (IPSS 0-7), sedang (IPSS 8-19) atau berat (IPSS 20-35) tergantung pada banyaknya gejala. Analisis data dilakukan dengan mengunakan analisis deskriptif untuk distribusi pasien dan analisis korelasi menggunakan uji korelasi Spearman.

\section{HASIL PENELITIAN}

Berdasarkan penelitian cross-sectional yang dilakukan di Poliklinik Bedah RSUP Prof. Dr. R. D. Manado selama bulan Desember, diperoleh data sebanyak 37 pasien yang sudah memenuhi kriteria inklusi, dan distribusinya dapat dilihat pada tabel 1.

Tabel 1.Distribusi Pasien Berdasarkan Umur

\begin{tabular}{ccc}
\hline Umur & $\begin{array}{c}\text { Jumlah } \\
\text { pasien }\end{array}$ & $\%$ \\
\hline $40-49$ & 0 & 0 \\
\hline $50-59$ & 1 & 2,7 \\
$60-69$ & 8 & 21,6 \\
$70-79$ & 23 & 62,2 \\
$80-89$ & 5 & 13,5 \\
\hline Total & $\mathbf{3 7}$ & $\mathbf{1 0 0 , 0}$ \\
\hline
\end{tabular}

Tabel 1 menunjukkan distribusi pasien $\mathrm{BPH}$ dengan LUTS berdasarkan umur yakni antara usia 40-89 tahun yang datang berobat di Poliklinik Bedah RSUP Prof. Dr. R. D. Kandou selama bulan Desember 2014, dan didapatkan golongan umur terbanyak berkisar antara umur 70-79 tahun sebanyak 23 pasien (62,2\%), diikuti golongan umur 60-69 tahun sebanyak 8 pasien $(21,6 \%)$, kemudian golongan umur 80-89 tahun sebanyak 5 pasien (13,5\%), golongan umur terendah pada usia 50-59 tahun sebanyak 1 pasien (2,7\%), dan pasien pada golongan umur 40-49 tidak ada (0\%).

Tabel 2 menunjukkan distribusi pasien berdasarkan derajat gejala yang dirasakan. Hasil yang didapatkan selama penelitian, bahwa pasien BPH dengan gejala LUTS yang datang berobat ke Poliklinik Bedah RSUP Prof. Dr. R. Kandou Manado terbanyak datang dengan derajat IPSS yang berat yakni 20 pasien $(54,1 \%)$, diikuti dengan pasien derajat sedang sebanyak 12 pasien (32,4\%), dan dengan derajat ringan sebanyak 5 pasien (13,5\%).

Tabel 2.Distribusi Pasien Berdasarkan Skor IPSS

\begin{tabular}{ccc}
\hline Derajat IPSS & $\begin{array}{c}\text { Jumlah } \\
\text { Pasien }\end{array}$ & $\mathbf{\%}$ \\
\hline Ringan & 5 & 13,5 \\
Sedang & 12 & 32,4 \\
Berat & 20 & 54,1 \\
\hline Total & $\mathbf{3 7}$ & $\mathbf{1 0 0 , 0}$ \\
\hline
\end{tabular}

Tabel 3 memperlihatkan distribusi pasien berdasarkan skor kualitas hidup (QoL) menunjukkan bahwa 10 pasien (27\%) merasa tidak senang dengan kualitas hidupnya, diikuti dengan 8 pasien $(21,6)$ yang merasa kualitas hidupnya berada pada skor buruk sekali, kemudian 7 pasien (18,9\%) yang pada umumnya merasa puas dengan kualitas hidupnya, lalu terdapat 4 pasien (10,8\%) dengan kualitas hidup campur yakni antara puas dan tidak, dilanjutkan dengan 4 pasien yang merasa tidak puas dengan kualitas hidupnya $(10,8 \%)$, untuk skor kualitas hidup senang terdapat 3 pasien $(8,1 \%)$, dan untuk skor senang sekali hanya terdapat 1 pasien $(2,7 \%)$.

Tabel 3.Distribusi Berdasarkan Skor QOL

\begin{tabular}{ccc}
\hline Skor QOL & $\begin{array}{c}\text { Jumlah } \\
\text { Pasien }\end{array}$ & $\mathbf{\%}$ \\
\hline Senang Sekali & 1 & 2,7 \\
Senang & 3 & 8,1 \\
Pada umumnya puas & 7 & 18,9 \\
Campur antara puas dan & 4 & 10,8 \\
tidak & 4 & 10,8 \\
Tidak puas & 10 & 27,0 \\
Tidak senang & 8 & 21,6 \\
Buruk sekali & $\mathbf{3 7}$ & $\mathbf{1 0 0 , 0}$ \\
\hline Total & &
\end{tabular}


Untuk melihat ada tidaknya hubungan antara skor IPSS dengan Quality of Life digunakan uji korelasi Spearman. Dari hasil Tabel 4, diperoleh korelasi yang bermakna (p < 0,005). Nilai korelasi Spearman sebesar 0,481. Hal ini menunjukkan bahwa adanya hubungan antara skor IPSS dengan skor Quality of Life.

Tabel 4. Hasil uji hubungan skor IPSS dengan QoL (Quality of Life) pasien BPH dengan gejala LUTS

\begin{tabular}{|c|c|c|c|c|}
\hline \multicolumn{3}{|c|}{ Correlations } & IPSS & QoL \\
\hline \multirow{6}{*}{ Spearman's rho } & \multirow{3}{*}{ Ipss } & Correlation Coefficient & 1,000 & $481^{* *}$ \\
\hline & & Sig. (2-tailed) & & ,003 \\
\hline & & $\mathrm{N}$ & 37 & 37 \\
\hline & \multirow{3}{*}{ QoL } & Correlation Coefficient &, $481^{* *}$ & 1,000 \\
\hline & & Sig. (2-tailed) & ,003 & ․ \\
\hline & & $\mathrm{N}$ & 37 & 37 \\
\hline
\end{tabular}

**. Correlation is significant at the 0.01 level (2-tailed).

\section{BAHASAN}

Benign Prostatic Hyperplasia atau yang biasa dikenal sebagai $\mathrm{BPH}$, meningkat $50 \%$ pada pria usia 50 dan insidensnya meningkat seiring bertambah usia. $^{8} \quad$ Beberapa instrumen telah dikembangkan untuk menilai derajat keparahan gejala pada pasien BPH, dan secara global kuesioner IPSS adalah salah satu instrumen yang paling sering digunakan. $^{7}$

Pada penelitian yang dilakukan selama bulan Desember 2014 di Poliklinik Bedah RSUP Prof. Dr. R. D. Kandou Manado, didapatkan 37 pasien yang bersedia menjadi responden. Dari 37 pasien ini, didapatkan bahwa golongan umur terbanyak berada pada kisaran antara umur 70-79 tahun, yakni sebanyak 23 pasien $(62,2 \%)$ dan yang terendah pada umur 50 59 tahun, yakni 1 pasien (2,7\%), dan pada kelompok usia 40-49 tahun tidak ada pasien. Hasil ini sedikit berbeda dari hasil penelitian yang dilakukan di RS Haji Adam Malik dan RS Pringadi Medan diadapatkan pasien terbanyak berada pada kelompok usia 60-70 tahun, yaitu sebanyak 27 pasien (51,9\%). ${ }^{9}$ Pada penelitian yang dilakukan di RS Dr. Kariadi, RS Roemani dan RSI Sultan Agung Semarang di dapatkan hasil yang sama dengan RS Haji Adam Malik dan RS Pringadi Medan, yakni kelompok umur paling banyak berada pada usia 60-69 tahun sebesar 32,7\%. ${ }^{9}$

Menurut penelitian dari Ozayar (2008), kelompok umur terbanyak berada pada umur 70-79 tahun. Kelompok umur yang sama seperti yang didapatkan oleh peneliti berdasarkan hasil penelitian di Poliklinik Bedah RSUP Prof. Dr. R. Kandou Manado.

Selanjutnya pasien diberikan kuesioner IPSS yakni, kuesioner atau sistem skoring yang direkomendasikanWHO untuk menilai derajat ringan-beratnya gejala yang dirasakan pasien. Kuesioner IPSS terdiri atas tujuh pertanyaan yang tiap gejalanya diberi skor antara 0-5. Hasil skor ini dapat menentukan apakah pasien berada pada kondisi gejala ringan, sedang, atau berat. ${ }^{3,8}$ IPSS sering digunakan dalam studi klinis untuk mengevaluasi prevalensi dari LUTS dan BPH dan juga untuk menilai efek dari terapi farmakologi, invasif minimal, dan terapi pembedahan untuk LUTS.

Distribusi frekuensi pasien $\mathrm{BPH}$ berdasarkan derajat gejala yang dirasakan oleh tiap responden bervariasi, hingga didapatkan bahwa dari 37 pasien yang datang 20 diantaranya datang dengan 
derajat yang berat $(54,1 \%)$ dengan skor IPSS berkisar antara 20-35, dan derajat ini adalah yang terbanyak. Hasil yang sama juga diperoleh pada penelitian yang menggunakan skor IPSS yang dilakukan oleh Nugroho (2012) menunjukkan derajat yang paling sering diderita oleh pasien BPH adalah derajat berat, sebesar 56\%.

Di RSUD Arifin Achmad Riau didapatkan derajat $\mathrm{BPH}$ yang paling banyak adalah derajat berat, yaitu sebanyak 32 pasien (53,3\%). ${ }^{10}$

Jarang ditemukan pasien yang datang berobat masuk dalam kategori derajat ringan. Hal ini disebabkan karena kebanyakan pasien datang berobat dan mencari pertolongan medis disaat gejala yang dirasakan sudah cukup mengganggu, sehingga akan lebih banyak didapatkan pasien-pasien $\mathrm{BPH}$ ini sudah berada pada derajat gejala LUTS yang berat.

Pada kuesioner IPSS dapat ditemukan satu pertanyaan tambahan, yakni skor QoL atau yang dikenal dengan indeks kualitas hidup. Indeks kualitas hidup terdiri atas tujuh kemungkinan jawaban, guna untuk menilai efek keseluruhan dari gejala atau tingkat ketidak-nyamanan yang dirasakan oleh pasien-pasien BPH.

Distribusi pasien berdasarkan skor QoL menunjukkan bahwa 10 pasien (27\%) merasa tidak senang dengan kualitas hidupnya, diikuti dengan 8 pasien $(21,6)$ yang merasa kualitas hidupnya berada pada skor buruk sekali. Hasil yang berbeda diperoleh dari penelitian yang dilakukan di RSUD Arifin Achmad, 58,3\% dari semua pasien BPH yang berpartisipasi menyatakan tidak puas dengan kualitas hidupnya. $^{10}$

Pada penelitian yang dilakukan di RS Haji Adam Malik Medan dan RS Pirngadi Medan didapatkan skor kualitas hidup pasien BPH yang berobat, 100\% berada pada perasaan tidak senang dengan fungsi berkemihnya. $^{9}$

Pasien BPH yang mencari pengobatan medis biasanya datang pada saat dirinya merasa bahwa gejala yang dirasakan sudah cukup menggangu aktivtas sehari-hari atau dengan kata lain, mengganggu kualitas hidupnya. ${ }^{7}$ Menurut Nugroho (2007) hal ini dikarenakan persepsi setiap orang atas gejala yang dirasakan cukup berbeda-beda. Menurut Chapple, faktor-faktor seperti pengetahuan akan penyakit $\mathrm{BPH}$, status ekonomi, sosial-budaya dari masingmasing negara yang berbeda mampu mempengaruhi pasien dalam merespon gejala yang dirasakan dan keinginan untuk berobat ke petugas medis. ${ }^{11}$

Pertanyaan mengenai kualitas hidup ini juga, membantu tenaga medis untuk menentukan langkah pengobatan selanjutnya. ${ }^{3,8}$

Oleh karena skor IPSS dan skor kualitas hidup digunakan untuk menentukan dasar penyakit BPH, yakni apakah gejala LUTS yang dinilai dengan IPSS tersebut mempengaruhi kualitas hidup dan langkah pengobatan selanjutnya, maka dilakukan uji hipotesis hubungan jumlah skor IPSS dengan skor dari indeks kualitas hidup (Quality of Life) menggunakan uji Spearman. Didapatkan bahwa korelasi bermakna $(p<0,005)$ dengan nilai korelasi sebesar 0,481 maka didapatkan bahwa ada terdapat hubungan antara skor IPSS dengan skor kualitas hidup (Quality of Life). Hasil yang sama juga diperoleh pada penelitian yang dilakukan di Poli Urologi RS Universitas Tribuhvan Nepal (2010), dimana terdapat korelasi yang kuat antara skor IPSS dengan QoL $(\mathrm{r}=0,429, \mathrm{p}=$ 0,001). ${ }^{12}$ Hasil yang sama juga ditemukan pada penelitian yang dilakukan di Jeju, Korea (2012), bahwa korelasi IPSS dengan QoL dinilai cukup berhubungan, dan secara statistik memiliki korelasi yang bermakna. $^{13}$

Hal ini menunjukkan bahwa memang sebagian orang datang mencari pengobatan medis disebabkan oleh derajat gejala yang dirasakan sudah cukup mengganggu kualitas hidup. ${ }^{8}$ Khususnya di Manado sendiri, kebanyakan pasien datang berobat pada saat BPH sudah masuk dalam derajat berat, dan diikuti dengan perasaan yang tidak senang. Keadaan seperti ini disebabkan oleh banyak faktor, antara lain faktor pengetahuan, ekonomi, atau sosial budaya. ${ }^{3}$ Berdasarkan data yang diperoleh 
dari penelitian, diketahui bahwa sebagian besar pasien menunjukkan tingkat sosialekonomi yang bisa dikatakan baik. Menurut peneliti, tingkat keparahan dan kualitas hidup yang dimiliki oleh pasienpasien yang berobat di Poli Bedah RSUP Prof. Dr. R. D. Kandou Manado salah satu faktor yang mempengaruhinya adalah tingkat pengetahuan akan penyakit BPH itu sendiri. Dan untuk memperkuat hal ini, perlu dilakukan penelitian selanjutnya.

\section{SIMPULAN}

Berdasarkan hasil penelitian pada pasien BPH dengan gejala LUTS yang berobat di Poliklinik Bedah RSUP Prof. Dr. R. D. Kandou Manado selama bulan Desember 2014 disimpulkan bahwa insiden BPH terbanyak berada pada kisaran umur 70-79 tahun. Derajat BPH yang paling sering adalah derajat berat. Nilai skor kualitas hidup yang sering dirasakan pasien, menunjukkan bahwa sebagian merasa tidak senang dengan kualitas hidupnya. Hubungan antara skor IPSS dengan Quality of Life pasien BPH dengan gejala LUTS melalui uji korelasi didapatkan bermakna ( $p<0,005)$, dengan nilai $\mathrm{r}=0,481$.

Faktor yang menjadi alasan mengapa pasien-pasien BPH dengan gejala LUTS yang berobat di Poli Bedah RSUP Prof. Dr. R. D. Kandou Manado datang dengan gejala dan kualitas hidup tidak senang ialah kurangnya pengetahuan tentang $\mathrm{BPH}$ itu sendiri.

\section{SARAN}

Pria yang telah melewati usia 40 tahun, dan mengalami gejala tidak mampu menahan kencing, sering terbangun malam untuk kencing, frekuensi kencing yang tidak normal, pancaran kencing yang lemah, pancaran kencing yang terputusputus, perasaan tidak puas setelah selesai berkemih, mengejan saat memulai kencing, disarankan untuk segera memeriksakan diri ke dokter atau rumah sakit daerah setempat. Deteksi dini berguna agar penyakit tidak semakin bertambah parah atau tidak sampai masuk pada derajat gejala yang berat.

\section{DAFTAR PUSTAKA}

1. Naderi N, Mochtar CA, de la Rosette JJ. Real life practice in the management of benign prostatic hyperplasia. CurrOpin Urol. 2004;14(1):41-44.

2. J de la Rosette, G Alivizatos, S Madersbacher, et al. Guidelines on Benign Prostatic Hyperplasia. European Association of Urology.2006:5.

3. Basuki B Purnomo. Dasar-dasarUrologi. Edisikedua. Jakarta: SagungSeto; 2009.

4. MK Li, Garcia LA, Rosen R. Lower urinary tract symptoms and male sexual dysfunction in Asia: a survey of ageing men from five Asian countries. BJU International. 2005.

5. Matthew BG, Alan W Partin, David YC. Lower Urinary Tract Symptoms (LUTS) and Benign Prostatic Hyperplasia (BPH). In: Robert G Moore, Jay T Bishoff, Stefan Loenig, Steven G Docimo, eds. Minimally Invasive Urological Surgery. USA: Taylor and Francis Group plc; 2005. p.545.

6. Alan J Wein, David Lee. Benign Prostatic Hyperplasia and Related Entities. In: Philip M Hanno, Alan J Wein, Bruce Malkowicz, eds. Penn Clinical Manual of Urology. Philadelphia: Elsevier Inc; 2007. p.483-504.

7. Roehrborn Claus G. Benign Prostatic Hyperplasia: An Overview. The University of Texas Southwestern Medical Center. Dallas, Tx, 2005.

8. Kapoor A. Benign prostatic hyperplasia (BPH) management in primary care setting. Can J Urol 2012;19(Suppl 1):10-17

9. Sinaga UM, B Harry, L Aznan. Majalah Kedokteran Nusantara. Volume 39; September 2006.

10. Fitriana N, Zuhirman, Suyanto. Hubungan Benign Prostate Hypertrophy dengan Disfungsi Ereksi di RSUD Arifin Achmad Provinsi Riau. Riau. Fakutltas Kedokteran Universitas Riau; Januari 2014.

11. Chapple C, Abrams P. Male Lower Urinary Tract Symptoms (LUTS). An International Consultation on Male LUTS. Société International 
Jurnal e-Clinic (eCl), Volume 3, Nomor 1, Januari-April 2015

d'Urologie; 2013.

12. Agwal CS, Chalise PR, Bhandari BB. Correlation of prostate volume with international prostat symptom scrore and quality of life in men with benign prostatic hyperplasia. Nepal Med Coll J 2008; (10)2: 104-107.
13. Huh Jung-Sik, Kim Yoong-Joo, Kim Sung Dae. Prevelance of Benign Prostatic Hyperplasia on Jeju Island: Analysis from a Cross-sectional Community based Survey Jeju International University. 